\title{
Curcumin and EGCG Suppress Apurinic/Apyrimidinic Endonuclease 1 and Induce Complete Remission in B-cell Non-Hodgkin's lymphoma Patients
}

\author{
Ahmad R. Bassiouny ${ }^{1}$, Mona A. Atteya ${ }^{1}$, Fatma H. El-Rashidy ${ }^{1}$, Hashem M. Neenaa ${ }^{2}$ \\ ${ }^{1}$ Department of Biochemistry, Faculty of Science, Alexandria University, Egypt; ${ }^{2}$ Department of \\ Internal Medicine, Hematological Disease Unit, Faculty of Medicine, Alexandria University, \\ Egypt
}

Corresponding author: Ahmad R. Bassiouny, PhD, Professor, Department of Biochemistry, Faculty of Science, Alexandria University, Egypt

Submission date: November 2, 2011; Acceptance date: December 12, 2011; Publication date: December 30, 2011

\begin{abstract}
:
Background: Follicular lymphoma (FL) is the most common subtype of indolent lymphoma. FL is still considered to be an incurable disease and palliation of symptoms is an acceptable approach to the expected pattern of repeated relapses due to developing resistance to chemotherapy agents. Apurinic/apyrimidinic endonuclease/redox factor-1 (APE1/Ref-1) is a multifunctional protein involved in DNA base excision repair (BER) of oxidative DNA damage and in redox regulation of a number of transcription factors. It was observed that cytoplasmic APE1 induced COX-2 expression through NF- $\mathrm{KB}$ activation. It has been shown that chemopreventive agents potentiate the efficacy of chemotherapy through the regulation of multiple signaling pathways, including NF- $\mathrm{B}$, c-Myc, cyclooxygenase-2, apoptosis, and others, suggesting a multitargeted nature of chemopreventive agents. We hypothesized that curcumin, a polyphenolic antioxidant derived from the spice turmeric, and epigallocatechin gallate (EGCG) from green tea would potentiate the effect of chemotherapy in B-cell lymphoma.
\end{abstract}

Objective: We examined the role of human apurinic/apyrimidinic endonuclease 1 (APE1) in resistance and prognosis in patients with FL. Our major objective was to update the safety and efficacy results of the antitumor effect of combination of curcumin and EGCG therapy in relapsed or resistant indolent or transformed non-Hodgkin follicular lymphoma patients and their peripheral blood mononuclear cells (PBMCs) compared with healthy donors' controls.

Methods: Thirty patients with FL with over-expression of constitutive active NF- $\kappa \mathrm{B}$ in their PBMCs received regular $\mathrm{CHOP}$ and consumed capsules compatible with curcumin doses between 0.9 and $5.4 \mathrm{~g}$ daily for up to 9 months and $9.0 \mathrm{~g} /$ day green tea whole extract "1000 $\mathrm{mg}$ tablets of green tea whole extract containing $200 \mathrm{mg}$ EGCG. We designed a dose-escalation 
study to explore the efficacy of $\mathrm{CHOP}$ in combination with curcumin and the green tea extract epigallocatechin-3 gallate (EGCG) on the viability of patients' peripheral blood mononuclear cells (PBMCs) lymphocytes.

Results: Treatment of patients with the combination of curcumin and EGCG, significantly lower cytoplasmic APE1 and the levels of the transcription factor were lower than those predicted from the effects of the CHOP agents (cyclophosphamide, doxorubicin, vincristine, and prednisone) alone, especially with a blunting of the remarkable increases in NF- $\kappa \mathrm{B}$ activation induced by CHOP. Eighteen of the patients had a CR (18/30), and twelve patients had PR (12/30) within 9 month treatment and followed up to 12 months. They remain disease-free a mean of $8.6 \mathrm{y}$ (range, 7.9-9.2 y) after this combination therapy.

Conclusion: Optimal patient benefit might be obtained in follicular lymphoma when administering curcumin up-front in combination with chemotherapy and EGCG treatment. The combination of curcumin with EGCG resulted in a synergistic antitumor activity and that with $\mathrm{CHOP}$ agents in additivity or sub-additivity, down-regulated the expression of all NF- $\mathrm{B}$ regulated gene products, leading to the suppression of angiogenesis, metastasis and entering in complete remission as indicated by $\beta 2$-microglobulin and lactate dehydrogenase (LDH) levels.

Key words: Curcumin, EGCG, B- cell NHL, NF-кB, VEGF, APE1, lymphoma

\section{INTRODUCTION:}

NHL is an increasing problem, now being the fifth most common malignancy in Egypt. Incidence have risen with age, due to the population agesing NHL has become increasingly common. The reason for the increase is not clear, but attention has focused on environmental factors. It is interesting to note that the Egyptians high rates of NHL among other populations may be due to the adverse environmental exposure and pollution in Egypt [1-2]. Improved understanding of the biology of normal B-cell development, and that B-cell NHL correspond to specific stages of normal B-cell development, has led to a more rational classification of B-cell malignancy [3]. About 1/3 of NHL have a follicular growth pattern, reminiscent of normal lymph node architecture, and these generally have an indolent clinical course, or low-grade histology [4]. The NHL Classification Project has defined the clinical features of the most common NHLs, which are (in order of frequency) diffuse large B-cell lymphoma (DLBCL) (31\%), follicular lymphoma (FL) (22\%), which are the most common types of B-cell lymphomas [5]. Currently, medical treatment for lymphoma revolves around the following therapies: chemotherapy, radiation and monoclonal antibodies (rituximab) [6, 7]. The standard chemotherapy regimen for NHL, known as CHOP, combines four agents: cyclophosphamide, doxorubicin, vincristine, and prednisone [8-9], but the disease is considered incurable with current therapeutic options. A clinical course is usually a series of remissions and relapses, with different treatments used for each relapse. Thus, new targeted treatments are vital to improving the clinical outcomes for patients with B-cell lymphoma. 
A better understanding of critical pathways and molecular mechanisms involved in B-cell lymphoma development, progression, and resistance to traditional therapy is critical. Reductionoxidation (redox) signaling systems are emerging as important targets in most cancers. AP endonuclease1/Redox effector factor 1 (APE1/Ref-1) is upregulated in human cancer cells and modulation of its redox activity blocks the proliferation and migration of cancer cells and cancerassociated endothelial cells in vitro [10]. Cells have several antioxidant systems including enzymes and redox-sensitive molecules (Trx, APE1/Ref-1) that protect the cells from oxidative stress [11]. Activation of APE1/Ref-1 increases the binding of oxidative stress regulating transcription factors (Hif-1, p53, Ap-1). There are many studies on the relationship between p53 and APE1/Ref-1 [12-13]. Oxidized APE1/Ref-1 facilitates p53 DNA binding. In contrast, p53 is a negative regulator of APE1/Ref-1 promoter. Despite accumulating evidence for the role of APE1/Ref-1 in redox regulation, the underlying mechanism is poorly understood. Furthermore, it has been shown that redox chaperone activity of APE1/Ref-1 is critical to NF-kB-mediated gene expression in human cells and is mediated through its physical association with target transcription factors. Thus, APE1/Ref-1 may play multiple roles in an anti-oxidative stress response pathway through its different biochemical activities. These findings also provide new insight into the mechanism of intracellular redox regulation [14].

Great interest is growing in identifying pharmacological agents that are able to modulate B cells and their microenvironment interactions that impact survival pathways in the hope of identifying potential novel therapies for treatment of B-cell lymphoma. Naturally occurring compounds are a potential source of agents that could modulate these survival signals and interrupt stromal nurturing. It was previously shown that the green tea extract, epigallocatechin-3 gallate (EGCG), the most abundant catechins in green tea credited with the majority of health benefits associated with green tea consumption, inhibits vascular endothelial growth factor receptor activation and induces apoptosis in primary CLL B cells [15]. This agent has now entered clinical testing in patients with early-stage CLL [16-17].

Another natural compound, curcumin (diferuloylmethane), derived from turmeric (Curcuma longa), together with EGCG are pharmacologically safe agents that have been found to be potent suppressors of nuclear factor kappa B (NF- $\mathrm{KB}$ ) activation and NF- $\mathrm{kB}$ gene products [18]. How these agents suppress NF- $\mathrm{KB}$ activation is becoming increasingly apparent. These inhibitors may block any one or more steps in the NF- $\mathrm{kB}$ signaling pathway, such as the signals that activate the NF- $\mathrm{kB}$ signaling cascade, translocation of NF- $\mathrm{kB}$ into the nucleus, DNA binding of the dimers, or interactions with the basal transcriptional machinery [19-20]. Patients with indolent NHL were considered a suitable population in which to test naturally dietary agents' curcumin and EGCG-based therapy initially, because there is often no urgent need for therapy. Since natural products-based therapy might be slow to act, an indolent disease would also permit a safe period of observation.

In the present study, we evaluated the antitumor effect of curcumin and EGCG in combination with chemotherapy on B-cell follicular lymphoma patients and their peripheral blood mononuclear cells (PBMCs).

\section{MATERIALS AND METHODS:}


Subjects and Study design: A total of 40 subjects participated in the present study. Ten subjects were considered the healthy control group, and 30 subjects of the same socioeconomic level, aged 25-61 years, were with NHL. All subjects were diagnosed by the staff of the Faculty of Medicine at The Department of Internal Medicine and Hematological Diseases at Alexandria University. Blood was obtained from FL patients who had provided written informed consent under a protocol approved by the ethics committee at Alexandria University according to the regulations of the ethical guidelines of the 1975 declaration of Helsinki. All B-cell NHL patients had a confirmed diagnosis using the International Workshop definition. Patients in this cohort had not been treated before blood processing for this study within the last two years. B-cell NHL cells were isolated from heparinized venous blood by density gradient centrifugation. Blood samples were withdrawn from all subjects (before (zero time), after three, six, nine, and twelve months of treatment), by vein puncture under complete aseptic conditions. Subjects included 18 males and 12 females, diagnosed with B-cell NHL at different stages (I-IV), and with histological subtypes (FML). Performance status (ECOG-PS) was assessed for all participants before and after treatment in numerical order from zero to five.

The extent of disease was coded according to the Ann Arbor staging system and assessed by clinical examination, the chest and abdomen computed tomography scan, and a bone marrow trephine biopsy. An analysis of prognostic factors has been performed on patients with high and intermediate grade non-Hodgkin's lymphoma (NHL) treated over a one-year period. Response to treatment was determined every three months of therapy, with the examinations necessary to verify the absence of abnormal findings at diagnosis. Response criteria for non-Hodgkin's lymphoma proposed by the International Workshop were applied.

During the study period, patients were treated with either CHOP or CHOP-based combination chemotherapy with either curcumin or curcumin and EGCG for nine months, and followed up to twelve months. CHOP resistance was defined as patients who had progression during first-line CHOP chemotherapy or relapse within six months after treatment. Patients were then on regular visits to the clinic every six months for necessary examinations to assure continuous remission. Blood samples were collected every three months for a one-year period. Attainment of complete remission (CR) was the most important predictor of overall survival; low serum lactate dehydrogenase (LDH), limited stage disease, and a high serum albumin were also independently associated with prolonged survival in multivariate analysis.

Furthermore, the effect of the studied herbal therapy to overcome the drug resistance of NHL-patients to chemotherapy was estimated via the determination of Glutathione S-Transferase (GST) activities. (GST) plays a central role in the defence against free radicals, peroxides and a wide range of xenobiotics and carcinogens. Hepatic and renal function tests were determined to evaluate the toxicity of herbal therapy, if present.

Reagents and Kits: The bFGF and VEGF kits were purchased from R \& D systems-(UK). $\beta_{2}-\mathrm{m}$ kit was purchased from Immunotech, (France). LDH kit was purchased from Diamond diagnostics-(Egypt). Green tea whole extract tablets were purchased from Techno-med Co. (Egypt). Curcuminoids $\mathrm{C}^{3}$ complex ${ }^{\circledR}$ capsules (95\%) were purchased from America's Finest, Inc. (USA). The biotinylated oligonucleotidic probe and rabbit anti-NF-KB antibodies were 
purchased from LiniLab. (Cairo, Egypt). BSA, EGTA, nonidet P-40, PMSF, protease inhibitors and tween-20 were purchased from Sigma Chemical Co. (USA).

Nuclear Fraction Preparation: The extraction of nuclear proteins was performed according to Dignam et. al., 1983 [21] procedure, by lysing the red blood cells (RBCs) in $1.0 \mathrm{ml}$ of cold RBCs lysis buffer $\left(8 \mathrm{mM}\right.$ Tris buffer, $\mathrm{pH} 7.2$ containing $\left.141 \mathrm{mM} \mathrm{NH}_{4} \mathrm{Cl}\right)$. Briefly the samples were vortexed for $30 \mathrm{sec}$, then centrifuged for $1 \mathrm{~min}$ at 10,000-12,000 $\times \mathrm{g}$ and red supernatants were poured off. To the white/red pellets, $2.0 \mathrm{ml}$ of RBCs lysis buffer were added and the tubes were vortexed for 2-3 sec to resuspend the pellets, then centrifuged for $30 \mathrm{sec}$ at 10,000-12,000 $\times \mathrm{g}$. All fluids were drained off, and this step was repeated until pellets became white/pink. The cells were lysed in hypotonic buffer $(10 \mathrm{mM}$ HEPES buffer, $\mathrm{pH} 7.5$ containing $10 \mathrm{mM} \mathrm{KCl}, 3 \mathrm{mM}$ $\mathrm{NaCl}, 3 \mathrm{mM} \mathrm{MgCl} 2,1 \mathrm{mM}$ EDTA, $1 \mathrm{mM}$ EGTA, $2 \mathrm{mM}$ DTT, $2 \mathrm{mM}$ PMSF, and protease inhibitor tablet) and on ice for $15 \mathrm{~min}$. Then 0.1 volume of $10 \% \mathrm{NP}-40$ was added and the tubes were vortexed for $10 \mathrm{sec}$ and centrifuged at $500 \times \mathrm{g}$ for $10 \mathrm{~min}$ at $4^{\circ} \mathrm{C}$. The supernatants (cytoplasmic extracts) were discarded, and the pellets were washed in $200 \mu$ l of hypotonic buffer and recentrifuged. The pelleted nuclei were resuspended in $50 \mu \mathrm{l}$ of ice-cold nuclear extract (NE) buffer (20 mM HEPES buffer, pH 7.5 containing $25 \%$ glycerol, $500 \mathrm{mM} \mathrm{KCl}, 1 \mathrm{mM} \mathrm{MgCl} 2,1 \%$ NP-40, $1 \mathrm{mM}$ EDTA, $2 \mathrm{mM}$ DTT, $2 \mathrm{mM}$ PMSF, and protease inhibitor tablet), and incubated on ice for $20 \mathrm{~min}$, with occasional mixing, then centrifuged at $14,000 \times \mathrm{g}$ for $15 \mathrm{~min}$ at $4^{\circ} \mathrm{C}$. The resulting supernatants (nuclear proteins) were aliquoted and stored at $-80^{\circ} \mathrm{C}$ for estimation of NF-кB.

Treatment of PBMN Cells with Curcumin and EGCG: Cell culture: The cell culture medium consisted of RPMI 1640 supplemented with $10 \%$ heat-inactivated fetal bovine serum, $10 \mathrm{mM}$ HEPES buffer, $2 \mathrm{mM}$ L-glutamine, $50 \mu \mathrm{g}$ of gentamicin/ml, $100 \mathrm{U}$ of penicillin $/ \mathrm{ml}, 100 \mu \mathrm{g}$ of streptomycin $/ \mathrm{ml}$, and $0.25 \mu \mathrm{g}$ of amphotericin $\mathrm{B} / \mathrm{ml}$. PBMC were isolated from whole blood by centrifugation through Ficoll-Hypaque solution. PBMC isolated from whole blood were washed twice in RPMI 1640, and resuspended in culture medium at a concentration of $10^{6} / \mathrm{ml}$. Then, $0.5 \mathrm{ml}$ of cell suspension was added to wells of a 24-well tissue culture plate. PBMN cells were treated with various doses of curcumin $(2.5-15 \mu \mathrm{mol} / \mathrm{L})$ or EGCG $(25-150 \mu \mathrm{mol} / \mathrm{L})$ individually or in combination using a constant ratio (1:10) for $24 \mathrm{~h}$. Cells were harvested, for further analysis. PBMN cells were treated with DMSO, curcumin $(20 \mu \mathrm{mol} / \mathrm{L}), \mathrm{EGCG}(100 \mu \mathrm{mol} / \mathrm{L})$, or sequentially with both drugs. For sequential treatment experiments, $1.0 \times 10^{6} \mathrm{PBMN}$ cells $/ \mathrm{mL}$ were treated with DMSO, curcumin $(10 \mu \mathrm{mol} / \mathrm{L})$ alone, EGCG $(100 \mu \mathrm{mol} / \mathrm{L})$ alone, or both agents for $24 \mathrm{~h}$; washed; and cultured for another $24 \mathrm{~h}$ in media alone or with the addition of the second agent (EGCG or curcumin), as indicated. Cells were then harvested for further analysis.

Determination of Serum LDH and $\mathbf{S}-\boldsymbol{\beta}_{2}$ microglobulin $\left(\boldsymbol{\beta}_{2}-\mathbf{m}\right)$ : LDH activity was determined kinetically according to the recommendation of the German society of clinical chemistry (1970) [22]. One milliliter of a working solution [buffer/substrate reagent (10 mM CAPSO buffer, $\mathrm{pH}$ 7.5 containing $10 \mathrm{mM}$ phosphate and $0.6 \mathrm{mM}$ pyruvate) was mixed with NADH reagent $(0.18$ mM NADH)] was added to $20 \mu \mathrm{l}$ serum sample in the cuvette, then mixed and the initial 
absorbance was measured after $30 \mathrm{sec}$ against air blank at $340 \mathrm{~nm}$., and after 1, 2 and 3 min other readings were taken for the determination of the mean absorbance change per min $(\Delta \mathrm{A} / \mathrm{min})$, which multiplied by 8095 to give the LDH activity in U/L.

Serum $\beta_{2}$-m levels were assayed by ELISA method of Benkirane et. al. (1990) [23]. Ten microliters of serum sample or standards were pipetted into the appropriate wells, and $200 \mu \mathrm{l}$ of enzyme conjugate were added per well, then the plate was incubated for $90 \mathrm{~min}$ at room temperature (RT), with constant shaking. The wells were then aspirated and washed three times. The substrate was added, the plate was incubated $30 \mathrm{~min}$ at RT with constant shaking, and then the stopping solution was added. Finally, the plate was monitored with an ELISA reader at 405$415 \mathrm{~nm}$ against substrate blank. The concentrations of serum $\beta_{2}-\mathrm{m}$ in $\mathrm{mg} / \mathrm{L}$ were estimated from the standard curve.

NF-кB ELISA Assay: NF-кB was determined using an NF- $\kappa B$ enzyme linked immunosorbent assay (ELISA)-based transcription factor assay kit according to the manufacturer's protocol [24]. The Non-Radioactive NFkB p50/p65 Transcription Factor Assay kit [TransAM ${ }^{\mathrm{TM}}$, Carlsbad, CA, USA, Catalog \# 40096 (p65)] is provided in a 96-well format. During the assay, the Capture Probe, a double stranded biotinylated oligonucleotide containing the consensus sequence for NFאB binding (5'-GGGACTTTCC-3'), is mixed with nuclear extract in the Transcription Factor Assay Buffer provided. When incubated together, the active form of NFkB contained in the nuclear extract, binds to its consensus sequence. After incubation, the biotinylated double stranded oligonucleotide bound by active NFkB protein is immobilized and any inactive, unbound material is washed away. The bound $\mathrm{NF \kappa B}$ transcription factor subunit $\mathrm{p} 65$ is detected with specific primary antibodies, a Rabbit anti-NFkB p65. A secondary horseradish peroxidase (HRP)-conjugated secondary antibody is then used for detection and provides sensitive colorimetric detection that can be read in a spectrophotometric plate reader. After incubation with developing solution, the reaction was stopped. Finally, the absorbance at $450 \mathrm{~nm}$ was read on the ELISA microplate reader.

VEGF and bFGF Assays: The determination of VEGF was carried out according to the procedure of Kondo et. al. (1994) [25] by using monoclonal antibodies specific for VEGF in a classical ELISA protocol. The concentrations of serum VEGF in $\mathrm{pg} / \mathrm{ml}$ were estimated from the standard curve. Human bFGF was determined using a competitive enzyme immunoassay (EIA) of R \& D systems-UK according to the manufacturer's instructions. The concentration of sera $\mathrm{bFGF}$ in $\mathrm{pg} / \mathrm{ml}$ was estimated from the standard curve.

Preparation of Total Cell Extract and Western Blot Analysis: In brief, cells were scraped in $500 \mu \mathrm{l}$ of lysis buffer (1\% triton X-100, $100 \mathrm{mM}$ EDTA, $150 \mathrm{mM} \mathrm{NaCl}, 50 \mathrm{mM}$ Tris-HCl pH 7.4, and complete mini protease inhibitor tablets-Roche), and incubated for $15 \mathrm{~min}$ at $4^{\circ} \mathrm{C}$ on a rocking platform; the cell lysates were then centrifuged at $20,800 \mathrm{~g}$ for $15 \mathrm{~min}$ at $4^{\circ} \mathrm{C}$, and the supernatant collected for protein quantitation using the Bradford reagent (Bio-Rad). Total cell extracts of the treated cells were used for analysis of APE1 and p53 proteins expression. $40 \mu \mathrm{g}$ proteins were subjected to $12.5 \%$ SDS-PAGE and transferred to a nitrocellulose membrane 
(Trans-Blot $0.2 \mu \mathrm{m}$; Bio-Rad). Signals were detected after a 1-hour exposure to anti-APE1 antibody (Santa Cruz Biotechnology). Rabbit monoclonal anti- $\beta$-actin (Sigma) (1:1000 dilution) antibody was used as an internal control. Followed by incubation with either peroxidaseconjugated anti-mouse or anti-rabbit antibody (Sigma) diluted at 1:2000). The bands were visualized according using a colorimetric detection kit.

RNA extraction and RT-PCR analysis: Total RNA was extracted from cultured lymphocyts cells using GStractTM RNA Isolation Kit II Guanidinium Thiocyanate Method according to the manufacturer guidelines.

Alterations in the APE1 and p53 levels in the treated cultured cells were determined using semi-quantitative reverse transcriptase PCR analysis. Using one-step RT-PCR reaction the synthesized cDNA was used for amplification of target gene(s) using specific primer sets for APE1, F: CTG CCT GGA CTC TCT CAT CAA TAC- R: CCT CAT CGC CTA TGC CGT AAG and for p53, F- CAC AGT CGG ATA TGA GCA TC - R: GTC GTC CAG ATA CTC AGC AT. Briefly, total RNA $(1 \mu \mathrm{g})$ and random primer $(2 \mu \mathrm{g})$ in DEPC water were denatured at $70{ }^{\circ} \mathrm{C}$ for $5 \mathrm{~min}$, then $10 \mu \mathrm{l}$ of reverse transcriptase buffer, $2 \mu 120 \mathrm{mmol} / \mathrm{L}$ dNTPs, $1 \mu \mathrm{M}$-MLV reverse transcriptase $(200 \mathrm{U})$ and DEPC water was added to the total volume of $20 \mu \mathrm{l}$. The reaction was performed at $42{ }^{\circ} \mathrm{C}$ for $1 \mathrm{~h}$ and at $94{ }^{\circ} \mathrm{C}$ for $5 \mathrm{~min}$ to inactivate the reverse transcriptase. PCR was performed in a $25-\mu 1$ reaction mixture containing $1 \mathrm{ml}$ reactant, $2.5 \mathrm{U}$ Taq DNA polymerase and $20 \mathrm{pmol}$ primers, and heated for $5 \mathrm{~min}$ at $95{ }^{\circ} \mathrm{C}$ for pre-denaturation, and then subjected to PCR cycles. PCR Products were analyzed on $2 \%$ agarose, stained with ethidium bromide and visualized by the UV-transilluminator.

MTT Viability Assay: Cell viability was assessed by an MTT assay. Lymphocytes were cultured into a 24-well plate, and treated with $\mathrm{CHOP}, \mathrm{CHOP}$ and curcumin or CHOP-Curcumin and EGCG. After twelve hours of incubation the cells (105/well) were washed twice with phosphate-buffered saline (PBS), and MTT (100 $\mu \mathrm{g} / 0.1 \mathrm{ml}$ of PBS) was added to each well. The cells were incubated at $37^{\circ} \mathrm{C}$ for four hours. The culture medium was then replaced with an equal volume of DMSO to dissolve formazan crystals. Absorbance was measured using a microplate reader at $550 \mathrm{~nm}$. The cell proliferation inhibition rate was calculated as 1 - (average OD value of wells with administered drug/average OD value of control wells) $\times 100$. All experiments were performed a minimum of three times and data was presented as the mean \pm SD.

GST Activity: GST activity was measured according to the method of Habig and Jakoby (26), using chlorodinitrobenzene (Sigma Chemical) as substrate. The formation of GSHchlorodinitrobenzene conjugate was monitored by the change in absorbance at $340 \mathrm{~nm}$. One unit of GST activity is the amount of enzyme catalyzing the conjugation of $1 \mu \mathrm{mol}$ substrate per minute. Samples were prepared as described above for GSH estimation without any acid treatment.

Statistical Analysis: Data is expressed as mean values \pm SEM. Differences between experimental groups were considered significant at a $p$ value $<0.05$ from the student's t-test. 


\section{RESULTS:}

CHOP, Curcumin and EGCG combination down-regulate NF-кB, reduce sera LDH and 及2m and modulate angiogenic factors levels: The aim of this study was to investigate the effect of both curcumin and EGCG on the B-cell NHL patients. Curcumin and EGCG were selected because they are pharmacologically safe agents that have been shown to down-regulate

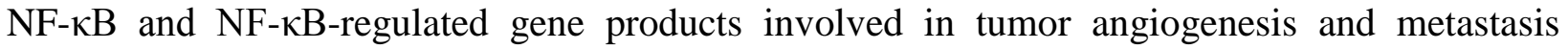
including VEGF and bFGF.
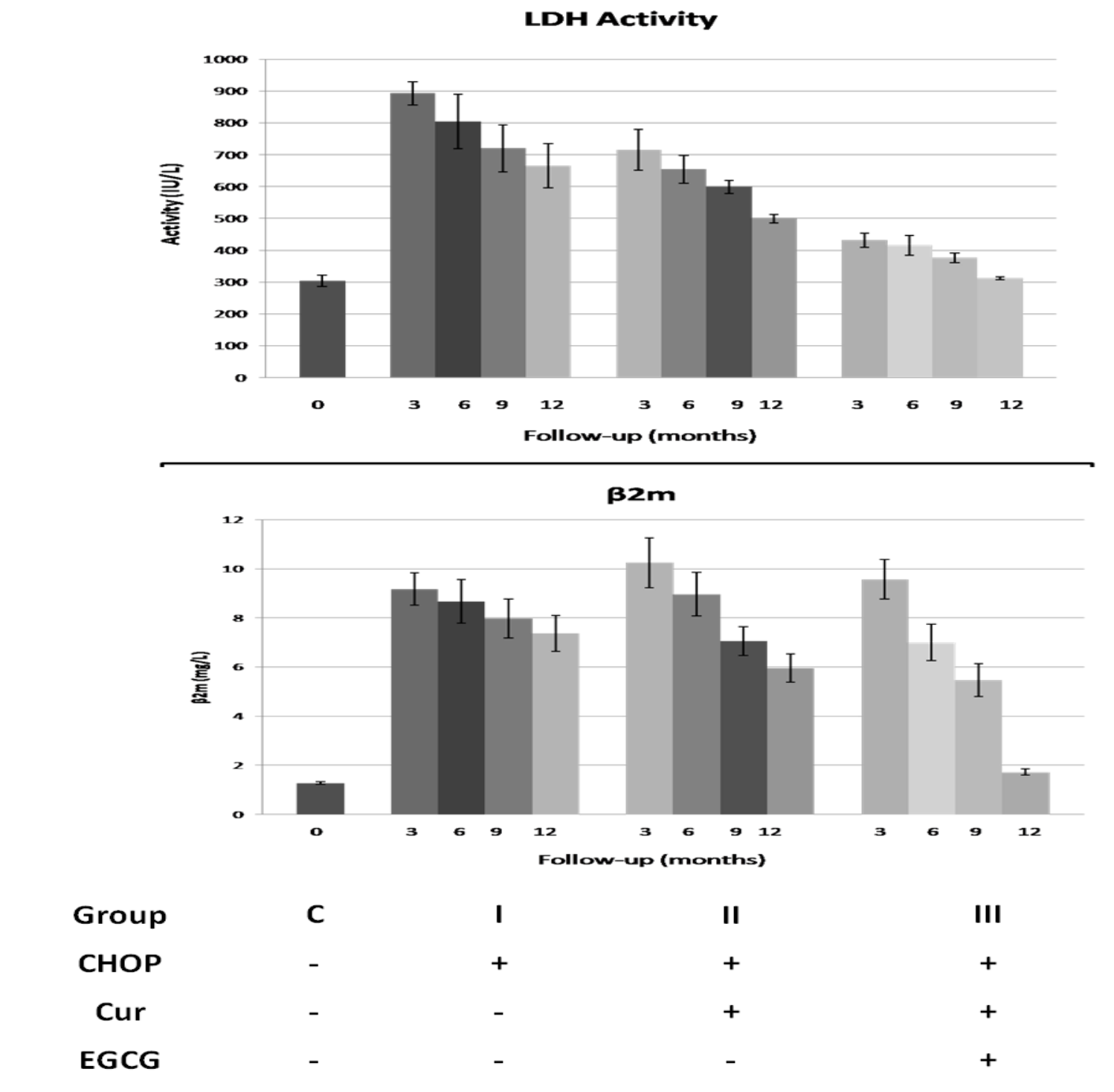

Figure 1: Changes in LDH and $\beta 2 \mathrm{~m}$ levels in sera samples of lymphoma patients. A significant elevation in both LDH and $\beta 2 \mathrm{~m}$ levels were observed in all groups of patients (I, II and III), in comparison to the control. A time-dependent reduction in both LDH and $\beta 2 \mathrm{~m}$ levels were observed during the treatment following the up period (three to six months). Group III of patients that received combination of CHOP, Curcumin and EGCG showed significant marked reduction compared to groups II and I. The results considered significant at $\mathrm{p}<0.05$ from the control and at $\mathrm{p}<0.01$ between the different groups. 
Constitutive activation of NF- $\kappa \mathrm{B}$ has been reported in a wide variety of cancers including lymphoid malignancies. We sought to determine whether curcumin alone, or in our CHOP combination suppressed such NF- $\kappa \mathrm{B}$ activation in PBMN cells from Follicular lymphoma patients.

As shown in Figure 2, the effect of Curcumin alone and in combination with EGCG was found to inhibit the activity of NF- $\mathrm{BB}$ and sensitized lymphoma patients to CHOP and induced remission.

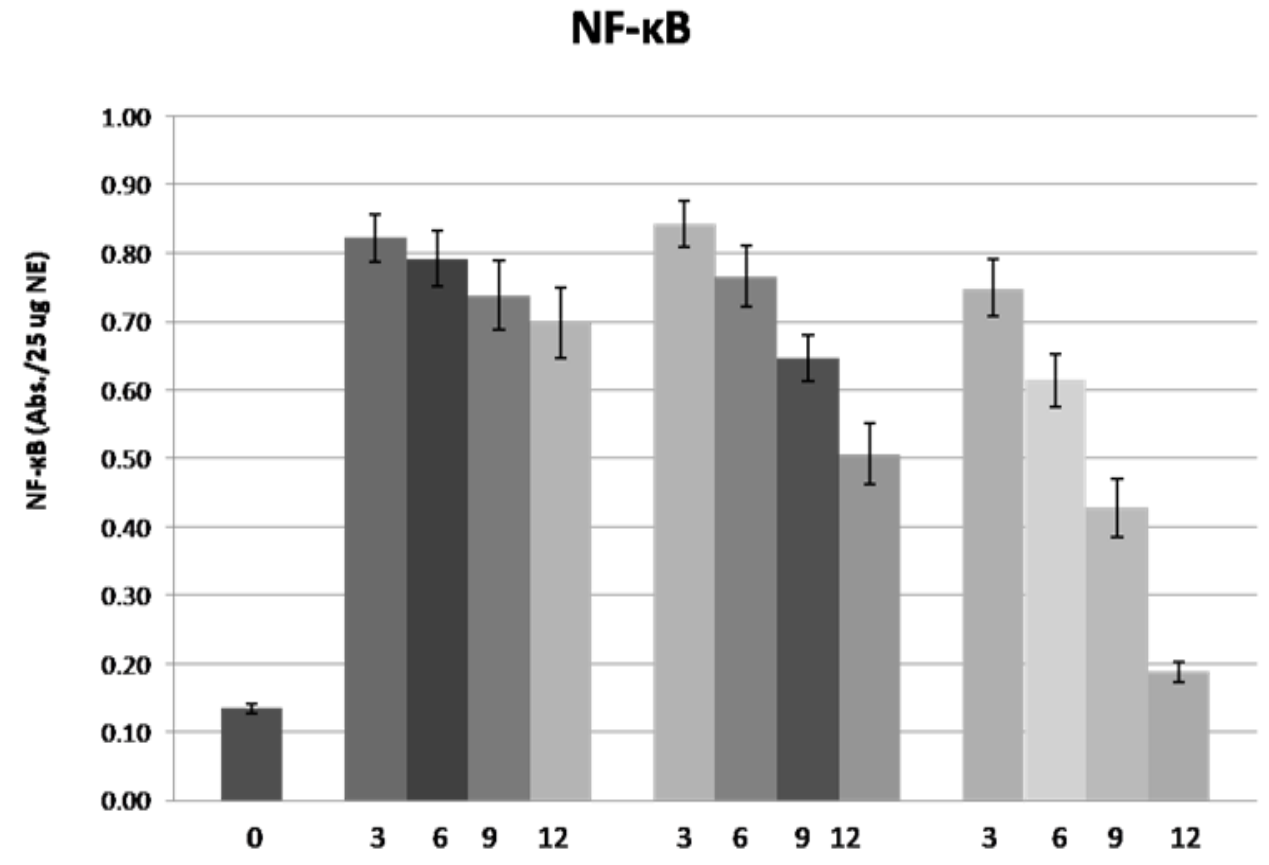

Follow-up (months)

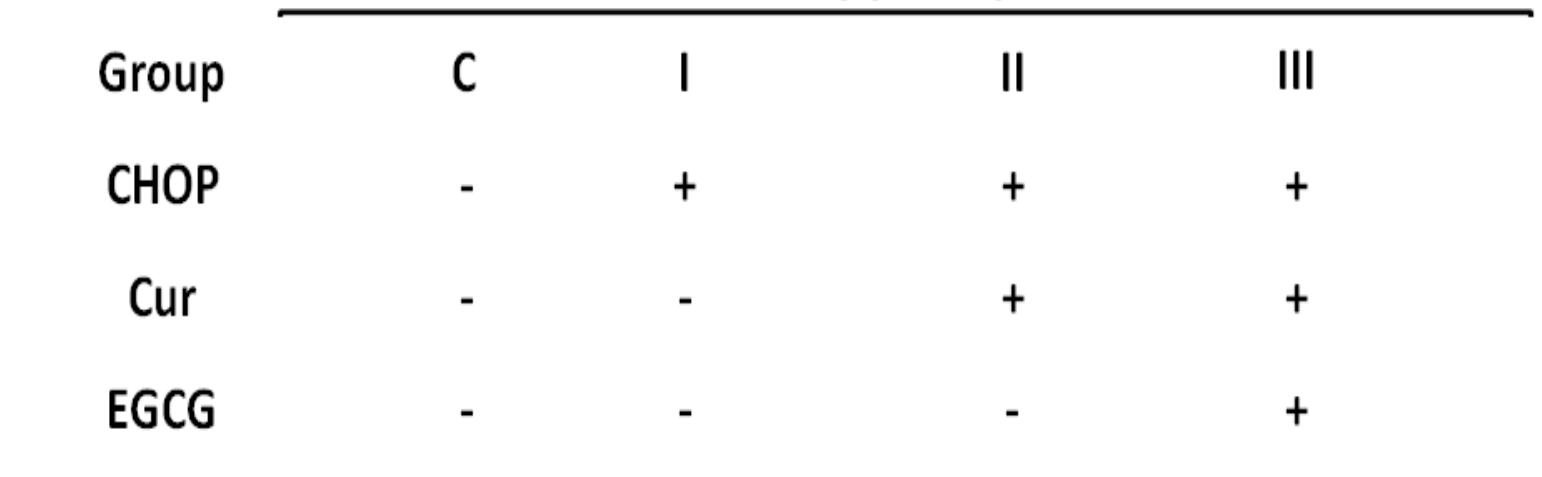

Figure 2: Results of the comparable groups in means \pm SEM, constitutive active NF- $\kappa B$ levels As we can see from figures 1 and 3 the combination of curcumin with EGCG resulted in a synergistic antitumor activity and that with $\mathrm{CHOP}$ agents in additivity or sub-additivity, downregulated the expression of all NF- $\mathrm{BB}$-regulated gene products, leading to the suppression of angiogenic factors VEGF and bFGF, metastasis and entering in complete remission as indicated by $\beta 2$-microglobulin and LDH levels. 

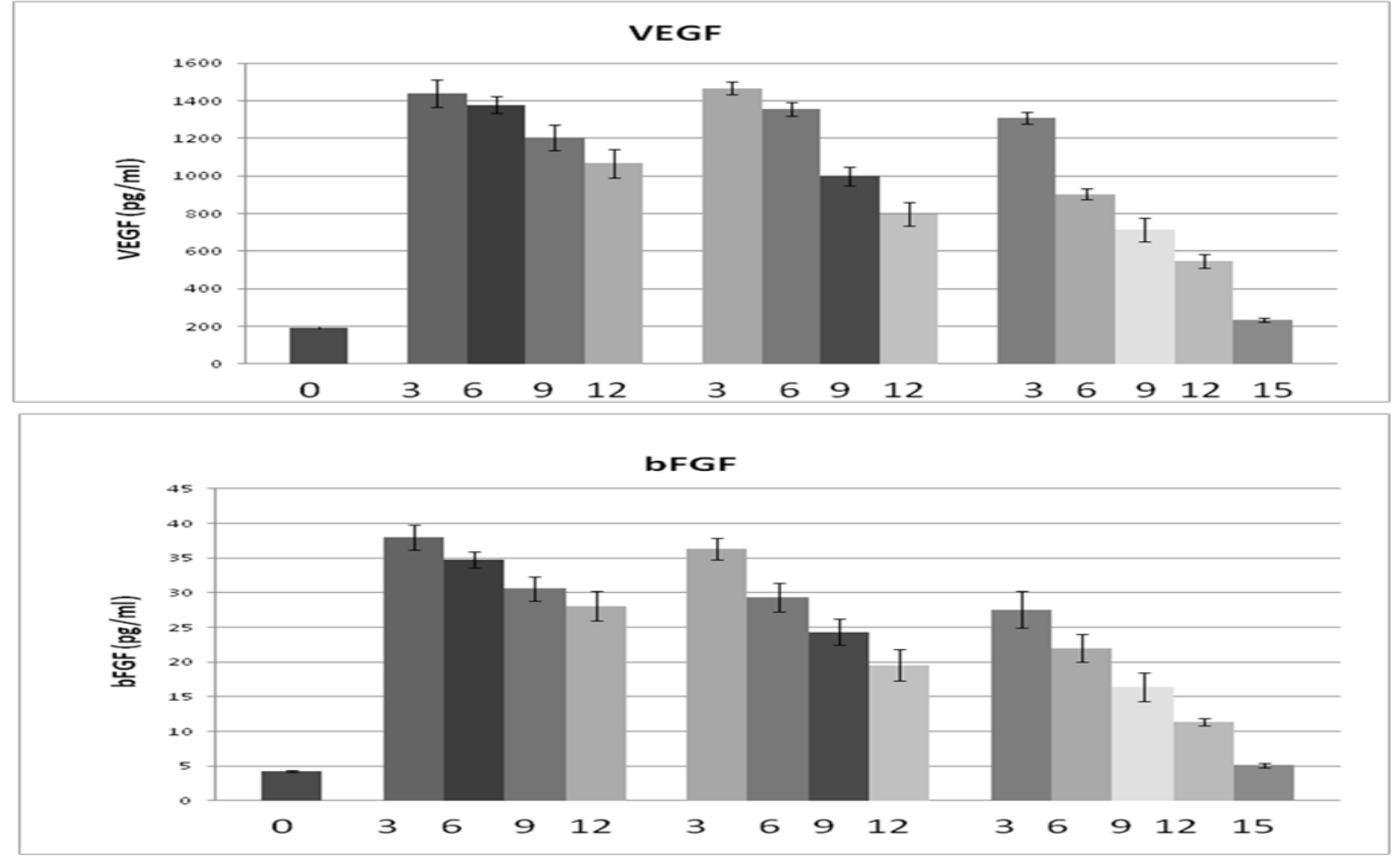

Follow up (months)

$\begin{array}{lllll}\text { Group } & \text { C } & \text { I } & \text { II } & \text { III } \\ \text { CHOP } & - & + & + & + \\ \text { Cur } & - & - & + & + \\ \text { EGCG } & - & - & - & +\end{array}$

Figure 3: Time-course study of the alterations in the angiogenic factors VEGF and bFGF in sera samples of NHL patients.

Alterations in the steady-state level of APE1 in NHL patients: APE1 western blotting analysis indicated marked elevation in its level in PMNCs of FL patients compared to the control. Representative data from four patients is shown in figure 4 . $\beta$-actin was used as an invariant internal control to validate the results.

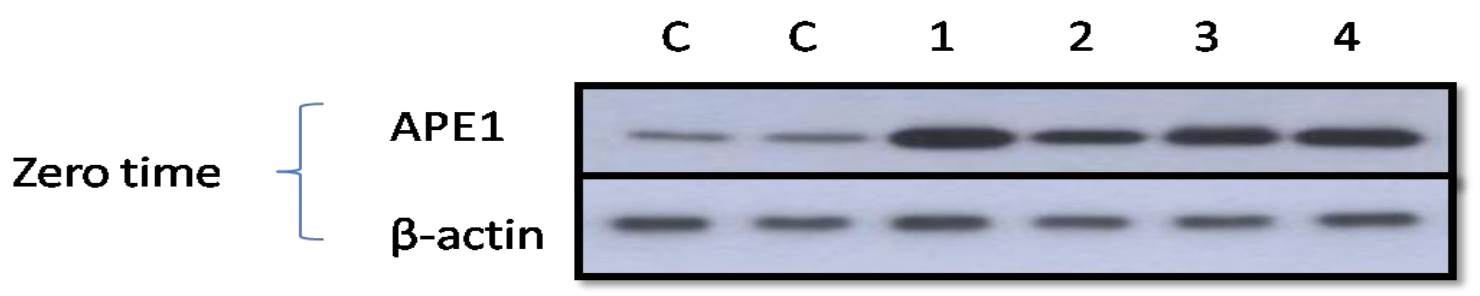

Figure 4: APE1 expression in lymph node cancer cells (Western blot). The total cell lysates are analyzed by Western blot. A representative samples from two controls and four patients (lanes 1 to 4) were shown. All four tested lymphoma patients express a dominant level of APE1. Normal PBMC express lower level of APE1 compared with these malignant lymphoma cells. 
Combination of CHOP, Curcumin and EGCG Modulate APE1 and p53 protein and mRNA levels in cultured PBMN cells and induce cell death. To study the potential effect of CHOP alone or in combination with curcumin and EGCG on the APE1 and p53 protein and mRNA levels, PBMN cells were treated with curcumin $(10 \mu \mathrm{mol} / \mathrm{L})$, EGCG $(100 \mu \mathrm{mol} / \mathrm{L})$, or sequentially with both drugs for 24 hours, washed, and cultured for another 24 hours in media alone or with the addition of the second agent (EGCG or curcumin). In the cells treated with CHOP only a marked elevation in APE1 protein and mRNA levels was observed as represented in figure 5. In the contrary a reduction of p53 protein and mRNA levels was observed. An addition of combination to cultured cells induced reduction in APE1 both at protein and mRNA levels as well as an increase in p53 protein and mRNA levels as shown in figure 5.

\section{I- Western Blot}

a) APE1

\author{
Patient \# \\ CHOP \\ $\mathrm{CHOP}+\mathrm{Cur}$ \\ CHOP+ Cur \& EGCG
}

II- RT-PCR

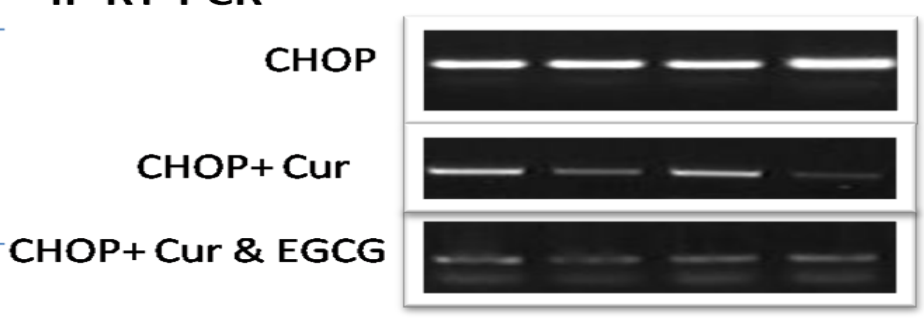

b) $\mathbf{p 5 3}$
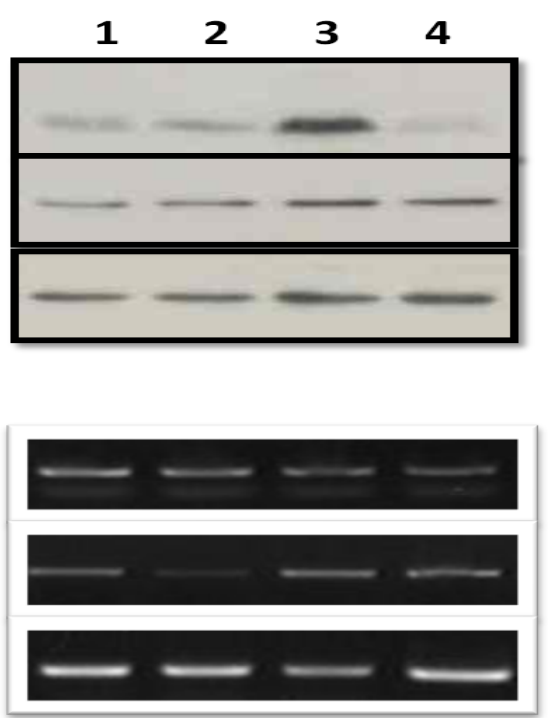

Figure 5: Western blotting and RT-PCR analyses of APE1 and p53 protein and mRNA levels in the cultured lymphocyte cells of 4 patients (lanes 1 to 4 ) collected zero time. Treatment of the cultured cells with combination CHOP, curcumin and EGCG for 12 hours induced marked reduction in APE1 both at protein and mRNA levels compared to the cells treated with either $\mathrm{CHOP}$ alone or CHOP and curcumin. Moreover, a marked increase in p53 protein and mRNA levels was observed in the same group, compared to the groups treated with CHOP alone or CHOP and curcumin.

We sought to determine whether curcumin treatment leads to cell death of follicular lymphoma PBMN cells. PBMN cells were cultured and treated with CHOP, CHOP and curcumin $20 \mu \mathrm{mol} / \mathrm{L}$ curcumin for 24 hours, or CHOP-Curcumin and EGCG in presence of and cell death was determined by MTT assay. The figure shows that significant loss of cell viability was seen at final concentrations of $20 \mu \mathrm{mol} / \mathrm{L}$ curcumin treatments in combination of EGCG and CHOP. Curcumin at $20 \mu \mathrm{mol} / \mathrm{L}$ for 48 hours also caused more apoptosis in patients' PBMCs compared with healthy donors' PBMCs $(\mathrm{P}<0.05)$. 


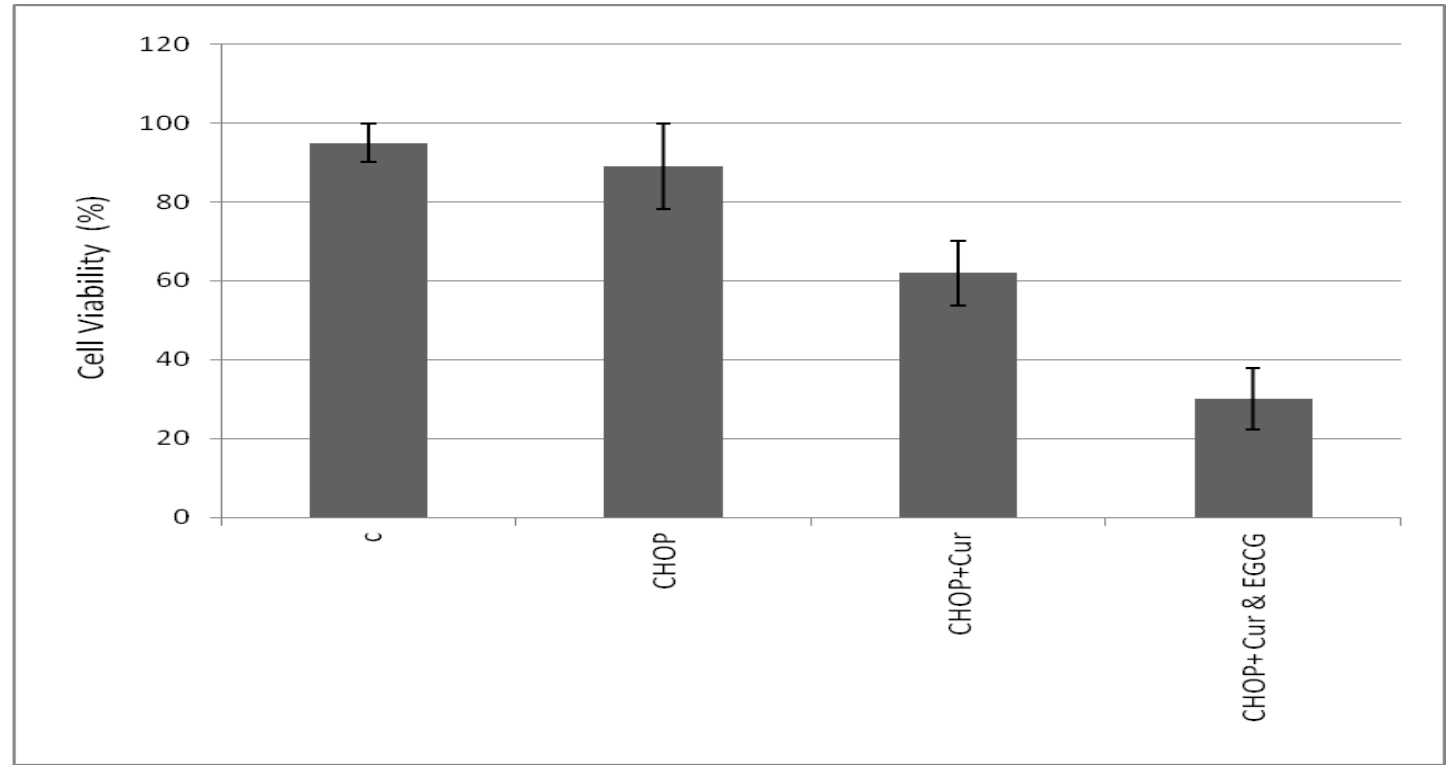

Figure 6: Cell viability of cultured PBMN cells. Treatment of patients' cells with combination of CHOP, Curcumin $(20 \mu \mathrm{mol} / \mathrm{L})$ and EGCG for nine months induced significant cell death versus the mock-treated, $\mathrm{CHOP}$, or $\mathrm{CHOP}$ and curcumin-treated cells. The reduction in the number of viable cells is significant at $\mathrm{p}<0.05$.

Furthermore, plasma Glutathione S-Transferase (GST) activities were estimated to show if the herbal therapy could overcome the chemo-resistance of NHL-patients.

\section{GST}

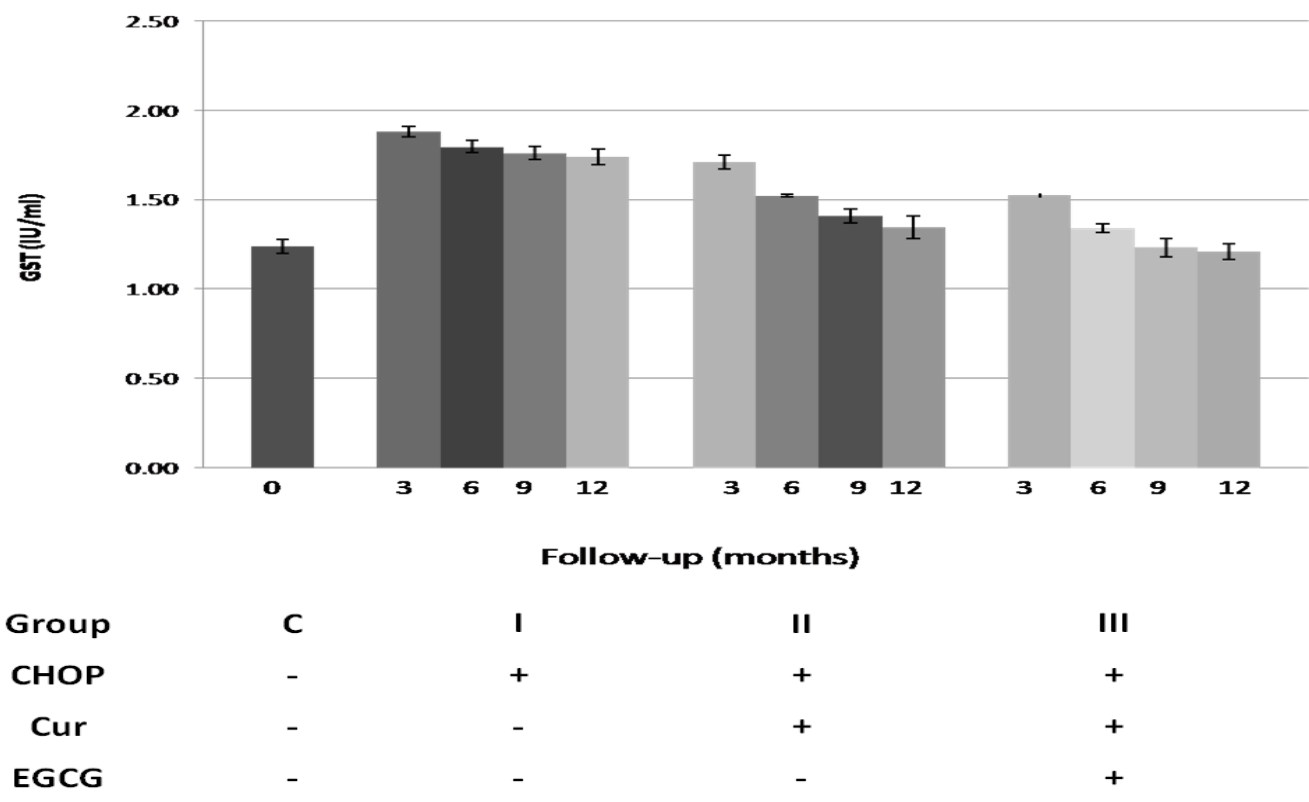

Figure 7: A time-course study of the alterations in the Glutathione S-Transferase activity in sera samples of NHL patients. Results are expressed as means and standard deviations. 
One of our major aims in this study was to assess the involvement of glutathione S-Transferase in patients through the course of treatment in the different groups. Figure 7 shows a marked elevation in GST activity in cancer patients receiving CHOP alone, compared to the controls. The addition of curcumin, EGCG improved its activity almost to a normal range within a nine month treatment.

\section{DISCUSSION:}

Drug resistance is a major cause of relapse and the incurability of cancer. The management of cancer involves procedures, which include surgery, radiotherapy, and chemotherapy. Development of chemo-resistance is a persistent problem during the treatment of local and disseminated disease. Gaining a better insight into the mechanisms of cancer resistance to chemotherapy might lead to new therapeutic targets and better anticancer strategies. Therapeutic strategies designed to increase the susceptibility of tumor cells to apoptosis have the potential to significantly augment the efficacy of a variety of cancer treatments.

The molecular mechanisms by which chemopreventive agents potentiate the antitumor effects of cancer therapies have not been fully elucidated. It is known that chemotherapy and radiotherapy can induce drug resistance in cancer cells, resulting in treatment failure. The major culprits involved in the development of drug resistance are the multidrug resistance gene, nuclear factor- $\mathrm{KB}$ (NF- $\mathrm{\kappa B}$ ), and Akt (27). We and other investigators have found that the enhanced antitumor effects by chemopreventive agents could be, in part, through the regulation of NF- $\mathrm{kB}$, Akt, and cyclooxygenase-2 (COX-2) pathways, which play important roles in cell survival (28, 29). Combination cytotoxic chemotherapy, the treatment of choice in these cases, results in a modest increase in survival at the cost of significant toxicity to the patient. This cytotoxic therapy, consisting of a standard chemotherapy regimen of NHL, which is known as CHOP (cyclophosphamide, doxorubicin, vincristine, and prednisone), was added to turmeric extract (curcumin), or to green tea extract (EGCG) (group III). This interesting polyphenolic compound and EGCG (the predominant and the major therapeutic agent of green tea polyphenols) are endowed with different molecular targets. In particular, it has been frequently reported that curcumin and EGCG may interfere with NF- $\mathrm{KB}$ activation and increase tumor cell response to different NF- $\mathrm{KB}$ activating anti-cancer drugs, including doxorubicin [30, 31]. This is in full agreement with our results (Figure 2).

The anti-cancer effect of curcumin has been shown, in part due to the suppression of cell proliferation, to cause the reduction of the tumor load and the induction of apoptosis in various cancer models both in vitro and in vivo [32-35]. Curcumin inhibits multiple levels within the transcriptional network to restrict cell proliferation. It induces p53-dependent apoptosis in various cancers of the colon, the breast, bladder, neuron, lung, ovary etc., although both p53dependent and -independent G2/M phase arrest by curcumin has been observed in colorectal cancer cells [36-39]. Curcumin arrested cell growth at the G2/M phase and induced apoptosis in human melanoma cells by inhibiting NFKB activation, and thus depletion of endogenous nitric oxide [32]. However, in mantle cell lymphoma curcumin has been found to induce G1/S arrest and apoptosis [38]. In $\mathrm{T}$ cell leukemia curcumin induced growth-arrest and apoptosis in association with the inhibition of constitutively active Jak-Stat pathway and NFKB [39-41]. In 
agreement with recent studies (32-41), figure 6 shows cell viability of cultured PBMN cells from the studied FL patients. Treatment of patients' cells with combination of CHOP, Curcumin and EGCG for 9 months induced significant cell death, versus the mock-treated, CHOP, or CHOP and curcumin-treated cells.

Concerning the patients treated with a combination of chemotherapy, curcumin and EGCG the serum levels of VEGF and bFGF were significantly higher than those of the control subjects before treatment. A significant reduction in both factors serum levels was observed in all patients receiving the combination of chemotherapy with the 2 natural dietary adjuvants as a first response of the treatment. Our results indicate that addition of curcumin to CHOP improved the international prognostic indices ( $\beta 2 \mathrm{~m}$ and LDH activity), and caused a high significant decrease in both groups of combination therapy after six and nine months of treatment, while with green tea, the effect was higher than that of curcumin alone. In the other hand, the chemotherapy treated group did not show any significant difference in both factors. The decrease in these parameters was a good prediction for complete remission (CR) rate and a well prognosis effect of both curcumin and green tea. We followed the patients for twelve months; eighteen of the patients had partial remission (PR-18/30), and twelve patients had complete remission (CR12/30).

GST, which is involved in the detoxification of electrophilic toxins and carcinogens, is increased in most of the human tumors studied. High concentrations of GST may rapidly detoxify anticancer agents, thereby preventing their cytotoxic action. Enhanced GST activity in follicular lymphoma samples (Figure 7) in our study supports ubiquitously-reported induction of GST, especially the isoenzyme GST-P in various cancer tissues and cell lines (42). GlutathioneS-Transferase (GST) activity showed a marked increase in the chemotherapy treated group after nine months of treatment, and followed up to twelve months (Figure 7), while in both curcumin and green tea treated group GST activity showed a significant decrease. This gives us an idea about the ability of both adjuvant therapies (curcumin \& EGCG) to overcome the resistance of NHL patients to chemotherapy. This was in agreement with the recent studies, which found that the inhibition of DNA bindings of both NF- $\mathrm{KB}$ and AP-1 transcription factors by curcumin should be responsible for a decrease in GST gene expression in malignant cells $(43,44)$. Green tea may have the same mechanism of inhibition like curcumin.

The evaluation of hepatic and renal function during the treatment courses in all of the studied groups indicated the absence of any side effect of the studied adjuvant therapy (curcumin and green tea) in combination with chemotherapy (data not shown). Our results agree with the results of the recent studies.

Overall, prognosis of advanced cancers such as ovarian cancer (45), hepatocellular carcinoma (46), breast, and lymphoma cancer remains poor. Regular chemotherapeutic modalities (such as alkylating agents and CHOP compounds) and ionizing radiation used in the treatment of these tumors induce DNA damage (such as base damage and others) in cells. The proficiency of cancer cells in DNA repair makes them able to repair such DNA damage and continue to survive. This is a significant cause for therapeutic resistance and impacts negatively on patient outcomes. Pharmacological inhibition of DNA repair is likely to enhance the cytotoxicity in cancer cells, and improve tumor response in patients. AP endonuclease1 (APE1), 
is a key enzyme in the base excision repair pathway. It hydrolyzes the phosphodiester backbone 5 ' to the AP site to facilitate repair (43-44). Additionally, APE1 also functions as a redox factor, known as Ref-1, to reduce and activate key transcription factors such as AP-1 (Fos/Jun), p53, HIF-1 $\alpha$ and others. Elevated APE1 levels in cancers are indicators of poor prognosis and chemotherapeutic resistance, and the removal of APE1 via methodology such as siRNA sensitizes cancer cell lines to chemotherapeutic agents [45]. Our hypothesis is that a small molecule inhibitor, such as curcumin of the DNA repair activity of APE1, will help elucidate the importance (role) of its repair function in cancer progression as wells as tumor drug response and will also give us a pharmacological tool to enhance cancer cells' sensitivity to chemotherapy. This report is the first data demonstrating a role of a BER protein, APE1, in lymphoma patients' survival and function after CHOP treatment.

APE1/Ref-1 has been implicated in the development and progression of various cancers [45-49]. AP endo activity is also significantly greater in high-grade than in low-grade tumors. Therefore, while the functional role of APE1/Ref-1 in FL is not completely understood, a biological relevance in lymphoma seems highly plausible. We explored the mechanistic and signaling pathways that may be involved in the response of PBMCs from FL patients to CHOP induced stress and the role of APE1 in this process. Our objective for choosing this pathway was based on the previously shown interactions between APE1 and p53 in tumor, and normal, dividing cells $[13,45$, because the p53 protein plays a major role in cellular response to DNA damage and other genomic aberrations, particularly in mitotically growing cells. The p53 tumor suppressor protein is a tetrameric nuclear phosphoprotein and phosphorylation of Ser15, a key phosphorylation target during the p53 activation process, has been shown as being critical for p53-dependent transactivation [50]. DNA damage induces phosphorylation of p53 at Ser15, and leads to reduced interaction between p53 and its negative regulator, oncoprotein MDM2 [44, 45]. We investigated this pathway by performing studies using Western blot analysis and found that altering APE1 levels leads to alterations in the amount of p53 (Fig.5). Our results indicate an induction of p53 after the alteration of APE1 levels and CHOP with curcumin and EGCG treatment. This change in p53 was correlated with modulation of APE1 and implicates this pathway as the primary signaling pathway involving APE1, CHOP, and ROS in PBMCs cells. In conclusion, curcumin selectively induces apoptosis in patients' PBMCs compared with healthy donors' controls. These events are associated with downregulation of angiogenic factors, inhibition of NF- $\mathrm{kB}$, decreased mRNA and protein expression of APE1 in FL cells. This is in total agreement with Zhang et al., 2010 (51) and our previous works (52, 53). Our findings provide a mechanistic rationale for the potential use of curcumin as a therapeutic agent for patients with FL.

Our study has some limitations where the observed association in FL alone may be a subgroup finding in Egyptian population due to chance. Therefore the finding requires validation in other independent cohorts. In addition, we did not evaluate the gene-environment interactions in lymphoma since the number of FL patients was small. However, replication of the finding should be warranted before proceeding to the gene-environment studies. Also, we have not completely delineated all the mechanisms that may be acting with APE1 perturbation in lymphoma. 
Acknowledgments: This work was partially supported by BA/CSSP postdoctoral research grant for the year 2010. The authors acknowledge the material and partial financial support of Alexandria University. We thank and recognize the excellent technical and research assistance of Dr. Amira Zaky, lecturer of Biochemistry at the Biochemistry Department, Faculty of Science, at Alexandria University, Egypt, for performing RT-PCR and western blotting analyses.

\section{CONCLUSION:}

Optimal patient benefit might be obtained in follicular lymphoma when administering curcumin up-front in combination with chemotherapy and EGCG treatment. The combination of curcumin with EGCG resulted in a synergistic antitumor activity and that with CHOP agents in additivity or sub-additivity, down-regulated the expression of all $\mathrm{NF}-\kappa \mathrm{B}$ regulated gene products, leading to the suppression of angiogenesis, metastasis and entering in complete remission as indicated by $\beta 2$-microglobulin and lactate dehydrogenase (LDH) levels. These data suggest that the combination of curcumin, EGCG and CHOP is highly effective palliative regimen for patients with FL with good performance status (score $\leq 3$ ). The findings herein present prognostic and therapeutic implications for treating follicular lymphoma. The APE1-inhibition results demonstrate the feasibility of the therapeutic modulation of APE1 using a variety of molecules and approaches. This report is the first data demonstrating a role of a BER protein, APE1, in lymphoma patients' survival and function after CHOP treatment. These results show that addition of curcumin and EGCG to CHOP achieved long-lasting remissions in 18 of 30 (60\%) FL lymphoma patients in relapse after 1 or multiple chemotherapies

\section{Conflict of Interest}

The authors state no conflict of interest.

\section{REFERENCES:}

1. Amr SS, Paolo B. (2006) Lymphoma and Leukemia. MECC Monograph 14, 131-9.

2. Coffey J, Hodgson DC. (2003) Therapy of non-Hodgkin's lymphoma. Eur J Nucl Med Mol Imaging 1, S28-S36.

3. Jaffe ES, Harris NL, Stein H, et al, eds. World Health Organization classification of tumors. Pathology and genetics: tumors of haemopoietic and lymphoid tissues. Lyon, France: IARC Press; 2008.

4. Armitage JO, Weisenburger DD. (1998) New approach to classifying non-Hodgkin's lymphomas: clinical features of the major histologic subtypes-Non-Hodgkin's Lymphoma Classification Project. J Clin Oncol 16, 2780-95.

5. Yunis JJ, Frizzera G, Oken MM, et al. (1987) Multiple recurrent genomic defects in follicular lymphoma: a possible model for cancer. N Engl J Med 316, 79-84.

6. Micallef IN, Maurer MJ, Wiseman GA, Witzig TE, et al. (2011) Epratuzumab with Rituximab, Cyclophosphamide, Doxorubicin, Vincristine, and Prednisone Chemotherapy in Patients with Previously Untreated Diffuse Large B-Cell Lymphoma. Blood 118(15), 4053-4061. 
7. Treon SP, Ioakimidis L, Soumerai JD et al. (2009) Primary therapy of Waldenström macroglobulinemia with bortezomib, dexamethasone, and rituximab: WMCTG clinical trial 05-180. J Clin Oncol 27, 3830-5.

8. Canellos GP. (2004) Lymphoma: present and future challenges. Semin Hematol 41, 2631.

9. Escalon MP, Liu NS. (2005) Prognostic factors and treatment of patients with T-cell nonHodgkin lymphoma. Cancer 103, 2091-98.

10. Fishel ML, Jiang Y, Rajeshkumar NV et al. (2011) Impact of APE1/Ref-1 Redox Inhibition on Pancreatic Tumor Growth. Mol Cancer Ther 10, 1698-708.

11. Kamata H \& Hirata H. (1999) Redox regulation of cellular signalling. Cell Signal 11, 114.

12. Seemann S \& Hainaut P. (2005) Roles of thioredoxinreductase 1 and APE/Ref-1 in the control of basal p53 stability and activity. Oncogene 24, 3853-3863.

13. Zaky A, Busso C, Izumi $\mathrm{T}$ et al. (2008) Regulation of the human AP-endonuclease (APE1/Ref-1) expression by the tumor suppressor p53 in response to DNA damage. Nucleic Acids Res 36, 1555-1566.

14. Kozue A, Satoshi H, Yasuaki K et al. (2008) A new APE1/ Ref-1-dependent pathway leading to reduction of NF-iB and AP-1, and activation of their DNAbinding activity. Nucleic Acids Research 36, 4327-4336.

15. Lee YK, Bone ND, Strege AK et al. (2004) VEGF receptor phosphorylation status and apoptosis is modulated by a green tea component, epigallocatechin-3-gallate (EGCG), in B-cell chronic lymphocytic leukemia. Blood 104, 788-94.

16. Shanafelt TD, Lee YK, Call TG et al. (2006) Clinical effects of oral green tea extracts in four patients with low grade B-cell malignancies. Leuk Res 30, 707-12.

17. Shanafelt TD, Kaufmann SH, Call TG et al. (2007) A phase I trial of daily oral green tea extract in asymptomatic, Rai stage 0-II patients with chronic lymphocytic leukemia. Blood 110, 610a.

18. Aggarwal BB, Shishodia S. (2006) Molecular targets of dietary agents for prevention and therapy of cancer. Biochemical pharmacology 71, 1397-1421.

19. Singh S, Aggarwal BB. (1995) Activation of transcription factor NF-kappa B is suppressed by curcumin (diferuloylmethane). J Biol Chem 270, 24995-5000.

20. Yang F, Oz HS, Barve S et al. (2001) The green tea polyphenol (-)-epigallocatechin-3gallate blocks nuclear factor-kappa B activation by inhibiting I kappa B kinase activity in the intestinal epithelial cell line IEC-6. Mol Pharmacol 60, 528-33.

21. Dignam JD, Lebovitz RM, Roeder RG. (1983) Accurate transcription initiation by RNA polymerase II in a soluble extract from isolated mammalian nuclei. Nucleic Acids Res $11,1475-89$.

22. Recommendation of German Society of Clinical Chemistry. Standard method for determining the activity of Lactate dehydrogenase. J Clin Chem Clin Biochem 1970; 8:658.

23. Benkirane M, Cordeil M, Prince P, et al. (1990) Immuno. Anal Biol Spec 20, 75. 
24. Patricia R, Isabelle E, Andree $\mathrm{H}$ et al. (2001) Development of a sensitive multi-well colorimetric assay for active Nuclear Factor-KB. Oxford University Press. Nucleic Acids Research 29, e21.

25. Kondo S, Asano M, Matsuo K et al. (1994) Vascular endothelial growth factor/ vascular permeability factor is detectable in the sera of tumor-bearing mice and cancer patient. Biochem Biophys Acta 1221, 211-4.

26. Habig WH, Jakoby WB. (1981) Assays for differentiation of glutathione S-transferase. Methods Enzymol 77, 398-407

27. Hazlehurst LA, Landowski TH, Dalton WS. (2003) Role of the tumor microenvironment in mediating de novo resistance to drugs and physiological mediators of cell death. Oncogene 22, 7396-402.

28. Satoh H, Nishikawa K, Suzuki K, et al. (2003) Genistein, a soy isoflavone, enhances necrotic-like cell death in a breast cancer cell treated with a chemotherapeutic agent. Res Commun Mol Pathol Pharmacol 113, 149-58.

29. Fazlul H. Sarkar and Yiwei Li. (2006) Using Chemopreventive Agents to Enhance the Efficacy of Cancer Therapy Cancer Res 66(7),3347-50

30. Bassiouny AR, Zaky AH and Neenaa H M. (2010) Synergistic Effect of Celecoxib on 5fluorouracil-induced Apoptosis in Hepatocellular Carcinoma Patients. Annals of Hepatology 9(4), 410-8.

31. Lagneaux L, Delforge A, Bron D et al. (1998) Chronic lymphocytic leukemic B cells but not normal B cells are rescued from apoptosis by contact with normal bone marrow stromal cells. Blood 91, 2387-96.

32. Chuang SE, Yeh PY, Lu YS et al. (2002) Basal levels and patterns of anticancer druginduced activation of nuclear factor-kB (NF-kB), and its attenuation by tamoxifen, dexamethasone and curcumin in carcinoma cells, Biochem Pharmacol 63, 1709-16.

33. Choudhuri T, Pal S, Das T, Sa G. (2005) Curcumin selectively induces apoptosis in deregulated cyclin D1-expressed cells at G2 phase of cell cycle in a p53-dependent manner. J Biol Chem 280, 20059-20068.

34. Pal S, Choudhuri T, Chattopadhyay S, Bhattacharya A, Datta G, Das T, Sa G. (2001) Mechanisms of curcumin-induced apoptosis of Ehrlich's ascites carcinoma cells. Biochem Biophys Res Commun 288, 658-665.

35. Dhillon N, Aggarwal BB, Newman RA, Wolff RA, Kunnumakkara AB, Abbruzzese JL, Ng CS, Badmaev V, Kurzrock R. (2008) Phase II trial of curcumin in patients with advanced pancreatic cancer. Clin Cancer Res 14, 4491-4499.

36. Aggarwal BB, Kumar A, Bharti AC. (2003) Anticancer potential of curcumin: preclinical and clinical studies. Anticancer Res 23, 363-398.

37. Moos PJ, Edes K, Mullally JE, Fitzpatrick FA. (2004) Curcumin impairs tumor suppressor p53 function in colon cancer cells. Carcinogenesis 25, 1611-1617.

38. Zheng M, Ekmekcioglu S, Walch ET, Tang CH, Grimm EA. (2004) Inhibition of nuclear factor-kappaB and nitric oxide by curcumin induces G2/M cell cycle arrest and apoptosis in human melanoma cells. Melanoma Res 14,165-171. 
39. Shishodia S, Amin HM, Lai R, Aggarwal BB. (2005) Curcumin (diferuloylmethane) inhibits constitutive NF-kappaB activation, induces G1/S arrest, suppresses proliferation, and induces apoptosis in mantle cell lymphoma. Biochem Pharmacol 70, 700-701.

40. Rajasingh J, Raikwar HP, Muthia G, Johnson C, Bright JJ. (2006) Curcumin induces growth-arrest and apoptosis in association with the inhibition of constitutively active JAK-STAT pathway in T cell leukemia. Biochem Biophys Res Commun 340, 359-368.

41. Tomita M, Kawakami H, Uchihara JN. (2006) Curcumin (diferuloylmethane) inhibits constitutive active NF-kappa B, leading to suppression of cell growth of human T-cell leukemia virus type I-infected T-cell lines and primary adult T-cell leukemia cells. Int $\mathrm{J}$ Cancer 118, 765-772.

42. Saydam N, Kirb A, Demir O, et al. (1997) Determination of glutathione, glutathione reductase, glutathione peroxidase and glutathione S-transferase levels in human lung cancer tissues. Cancer Lett 119, 13-9.

43. Duvoix A, Morceau F, Delhalle S., M. Schmitz, Schnekenburger M, Galteau MM, et al., (2003) Induction of apoptosis by curcumin: mediation by glutathione S-transferase P1-1 inhibition, Biochem. Pharmacol. 66, 1475-1483.

44. Duvoix A, Morceau F, Schnekenburger M, Delhalle S, Galteau MM, Dicato M, Diederich M, (2003) Curcumin-induced cell death in two leukemia cell lines: K562 and Jurkat, Ann.NY Acad. Sci. 1010, 389-392.

45. Fishel ML, He Y, Reed AM, Chin-Sinex H, Hutchins GD, Mendonca MS, Kelley MR. (2008) Knockdown of the DNA repair and redox signaling protein Ape1/Ref-1 blocks ovarian cancer cell and tumor growth. DNA Repair (Amst) 7(2), 177-186.

46. Di Maso V, Avellini C, Crocè LS, Rosso N, Quadrifoglio F, Cesaratto L, Codarin E, Bedogni G, Beltrami CA, Tell G, and Tiribelli C. (2007) Subcellular Localization of APE1/Ref-1 in Human Hepatocellular Carcinoma: Possible Prognostic Significance. Mol Med. 13(1-2), 89-96

47. Luo M, Delaplane S, Jiang A, Reed A, He Y, Fishel M, Nyland RL, Borch RF, Qiao X, Georgiadis MM, et al. (2008) Role of the multifunctional DNA repair and redox signaling protein Ape1/Ref-1 in cancer and endothelial cells: small-molecule inhibition of the redox functions of Ape1. Antioxid Redox Signal, 10(11), 1853-1867.

48. Wang D, Luo M and Kelley MR. (2004) Human apurinic endonuclease 1 (APE1) expression and prognostic significance in osteosarcoma: Enhanced sensitivity of osteosarcoma to DNA damaging agents using silencing RNA APE1 expression inhibition. Mol Cancer Ther 3; 679

49. Tell G. (2009) The many functions of APE1/Ref-1: not only a DNA repair enzyme. Antioxid Redox Signal 11,601-20

50. Tell G, Fantini D, Quadrifoglio F. (2010) Understanding different functions of mammalian AP endonuclease (APE1) as a promising tool for cancer treatment. Cell Mol Life Sci. 67(21), 3589-608.

51. Seo YR, Kelley MR, Smith ML. (2002) Selenomethionine regulation of p53 by a ref1dependent redox mechanism. Proc Natl Acad Sci U S A 99, 14548-53. 
52. Zhang C, Li B, Zhang X, Hazarika P, Aggarwal BB, and Duvic M. (2010) Curcumin Selectively Induces Apoptosis in Cutaneous T-Cell Lymphoma Cell Lines and Patients'

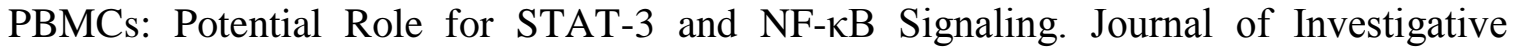
Dermatology 130, 2110-2119.

53. Bassiouny AR, Zaky AZ, Abdulmalek SA, Kandeel KM, Ismail A, Moftah M. (2011) Modulation of AP-endonuclease1 levels associated with hepatic cirrhosis in rat model treated with human umbilical cord blood mononuclear stem cells. Int J Clin Exp Pathol 4(7), 692-707

54. Bassiouny AR, Zaky AZ, Fawky FM, Kandeel KM. (2011) Alteration of APendonuclease 1 expression in curcumin-treated fibrotic rats. Annals of Hepatology, 10 (4), 516-530. 